\title{
Citrus limetta peels: a promising substrate for the production of multienzyme preparation from a yeast consortium
}

\author{
Maria Shariq and Muhammad Sohail ${ }^{*}$ (1)
}

\begin{abstract}
Citrus limetta peels (CLP), a waste material generated by juice industries, has scarcely been reported for the production of yeast enzymes. The study was conducted to obtain a multienzyme preparation from a yeast consortium under solid-state fermentation of CLP. The substrate, CLP, was pretreated using either acid or alkali, and factors affecting production of multienzyme were studied by generating two separate Plackett-Burman designs. Since, alkali-pretreated CLP yielded higher titers; therefore, significant factors affecting multienzyme preparation using this substrate were optimized by employing Box-Behnken design. The analysis revealed that under optimized conditions, i.e., cultivation of yeast strains for $72 \mathrm{~h}$ to alkali-pretreated CLP moistened with mineral salt medium having $\mathrm{pH} 5$ yielded more than $10 \mathrm{IU} \mathrm{mL} \mathrm{mL}^{-1}$ of cellulase, xylanase, and amylase. The multienzyme was studied for its application to saccharify fruit and non-fruit wastes and for orange juice clarification. The data showed that the enzyme preparation could release $3.03 \mathrm{mg} \mathrm{L}^{-1} \mathrm{~h}^{-1}$ of reducing sugars from various crude substrates and was able to reduce turbidity of orange juice by $11 \%$ with substantial decrease in viscosity and acidity. Hence, CLP appeared as a promising substrate to produce multienzyme preparation from yeast consortium.
\end{abstract}

Keywords: Box-Behnken design, Citrus limetta, Multienzyme preparation, Plackett-Burman design, Saccharification, Yeast consortium

\section{Introduction}

Solid-state fermentation (SSF) or cultivation of microorganism on solid materials in the absence of free water has remained a promising technology in eastern hemisphere of the globe for many centuries and is still considered as an attractive process for the countries like India and Pakistan (Manan and Webb 2017). Indeed, availability of agro-industrial wastes with the requirement of technologically simple bioreactors renders the development of SSF-based processes to get due attention in such countries. Among various waste materials, brans, straws, bagasses, and fruits peels have been studied extensively as raw materials under SSF (Ferreira et al. 2016); the choice of specific substrate, however, depends on the product and local agriculture practices.

*Correspondence: msohail@uok.edu.pk

Department of Microbiology, University of Karachi, Karachi 75270, Pakistan
The utilization of fruit peels as fermentation raw material offers benefits for being cost-effective and can provide additional revenues to food-processing industries. Various literature reports (Li et al. 2015; Sagar et al. 2018) describe fermentative production of multienzyme using fruit peels such as those of Mango (Mangifera indica), Pomegranate (Punica granatum), Apple (Malus pumila), Mosambi (Citrus limetta), Banana (Musa acuminate), and Orange (Citrus reticulata). Pakistan being sixth largest citrus fruit producer can be benefitted by the development of fermentation processes based on fruit juice industry's waste. Indeed, the cultivation area of citrus fruits in Pakistan has been increased from 33,000 to $197,450 \mathrm{Ha}$ in 2012; consequently the production reached to 115.52 million MT that accounts for $4 \%$ of global production (Yasin Ashraf et al. 2013). Hence, the country holds large citrus juice industries that generate waste including fruit peels in abundant quantities. 
The waste, peels of most of the citrus fruits, accounts for $\sim 50 \%$ of total fruit weight (Oberoi et al. 2010), but it does not attain any commercial importance and is largely used as cattle feed or disposed as municipal waste (Oberoi et al. 2010; Sharma 2012). It contains fermentable sugars including glucose, fructose, and sucrose along with insoluble polysaccharides pectin and cellulose (Grohmann et al. 1995) with low levels of non-fermentable components such as lignin. Amongst citrus wastes, the waste of Citrus reticulata is a well-studied substrate for the enzyme and ethanol production under solid-state and submerged fermentation (Oberoi et al. 2011; Sandhu et al. 2012); however, Citrus limetta has not been frequently described, particularly under SSF.

Solid-state fermentation provides microorganism conditions similar to their natural environment where members in a consortium interact synergistically, and hence, complex substrates can be degraded effectively (Sutherland 2001) and cellulosic ethanol can be obtained (Lynd et al. 2002). It has also been reported that one strain in a consortium utilizes toxic or undesirable by-product produced by the other strain (Herrero et al. 1985), and hence, higher yields are obtained (Sadhu 2013). Moreover, the consortium yields multiple products in a single pot, such as, more than three plant cell wall degrading enzymes (PCWDEs) can be produced (Rehman et al. 2014). A heterogeneous enzyme preparation is benefitted by integrated activities and co-operativity among its components, and is suitable to be applied to saccharify crude lignocellulosic substrates (Zhang et al. 2004).

Production of an enzyme under SSF is affected by a number of factors which are traditionally studied by labor- and time-intensive strategy in which one factor is varied at a time. Optimization of production of multiple enzymes from a single process without using statistical approaches cannot be carried out conveniently. Indeed, statistical tools for design of experiments (DoE) can be used to investigate the effect of different variables on the production of enzyme cocktails in relatively fewer numbers of experiments (Pirzadah et al. 2014). DoE tools including Plackett-Burman design (PBD) and response surface methodology (RSM) have been employed earlier to produce pectinase from a yeast using commercially available pectin as substrate (Ahmed et al. 2019).

Penetration into solid substrates through hyphae renders fungi suitable organism to be utilized under SSF (Raimbault 1998). Yeasts, on the other hand, have been traditionally used for submerged fermentation processes. The yeast-based SSF processes offer an advantage as these can be completed in a shorter duration and can be extended to proceed for consolidated bioprocessing to obtain ethanol directly from crude substrates (Shariq and Sohail 2018). Earlier, the yeast strains Saccharomyces cerevisiae MK-157 and Candida tropicalis MK-118 were co-cultured to produce cellulase and xylanase under SSF of sugarcane bagasse (Qadir et al. 2018). In this manuscript, the production of multienzyme preparation from a consortium of MK-157, MK-118 and C. tropicalis MK-160 under SSF of CLP is reported. The factors affecting production of the enzyme cocktail were screened using PBD and the levels of significant factors were optimized by employing Box-Behnken design (BBD) in RSM approach.

\section{Materials and methods \\ Yeast consortium}

Three of the indigenous yeast strains, C. tropicalis MK-118 and MK-160 and S. cerevisiae MK-157 were retrieved from the culture collection available in the lab of the corresponding author. MK157 was previously reported for its ability to produce endoglucanase (EG) (Shariq et al. 2018) MK-160 for xylanase (Xyl) (Shariq and Sohail 2018), and MK-118 for EG, $\beta$-glucosidase (BGL) and Xyl production (Shariq and Sohail 2020). All the three strains were maintained on Sabouraud's dextrose agar (SDA). The suitability of the three yeast strains to be co-cultured was evaluated by cross streaking on SDA plates.

Inoculum was prepared by separately inoculating the isolated colonies of MK-118, MK-157, and MK-160 in $\mathrm{SDB}$, and incubating at $30{ }^{\circ} \mathrm{C}$ for $24 \mathrm{~h}$ with shaking at $150 \mathrm{rpm}$. The density of cultures was checked at $600 \mathrm{~nm}$ against blank and maintained at 1.0 for inoculating in the medium of production. As given in DoE, either 0.25 or $0.5 \mathrm{~mL} \mathrm{~g}^{-1}$ of substrate was transferred for multienzyme production.

\section{Preparation of the substrate}

Different fruit wastes including peels of Mango, Pomegranate, Apple, Sweet Lime (CLP), Banana, and Orange were locally collected and chopped in 1-2 cm pieces, washed with excessive tap water to remove any chemical contaminants and residual sugars. After washing, the materials were solar dried and then placed in an oven at $60{ }^{\circ} \mathrm{C}$ for overnight. Dried materials were ground and passed from $100 \mu \mathrm{m}$ mesh size sieve.

Since, higher titers of the enzymes were obtained by the SSF of CLP, therefore, this waste was further exploited. Before its utilization for multienzyme production, CLP was pretreated separately with $0.5 \%, 0.75 \%$, and $1 \%$ of sulfuric acid or sodium hydroxide by keeping the material in acid or alkali (at the rate of $50 \mathrm{~mL} \mathrm{~g}^{-1}$ ) at room temperature for $24 \mathrm{~h}$. The slurry was then washed excessively with tap water until the $\mathrm{pH}$ of the wash-through became neutral. The washed slurry was oven dried at $60{ }^{\circ} \mathrm{C}$ and clumps were grinded to powder, if needed. 


\section{Solid-state fermentation}

Solid-state fermentation was performed with $1 \mathrm{~g}$ of native and chemically pretreated CLP in $100 \mathrm{~mL}$ Erlenmeyer flasks, sterilized by autoclaving for $30 \mathrm{~min}$, and moistened with mineral salt medium (Qadir et al. 2018), or with $0.5 \%$ yeast extract and $0.5 \%$ peptone (YEP). The experiments were performed as given in statistical designs (PBD or $\mathrm{BBD})$.

Initially, PBD was adopted for screening of significant factors that affected EG, BGL, Xyl, amylase, and pectinase production from yeast consortium of MK-118, MK-157, and MK-160 under SSF of CLP. Two different PBDs (each comprised of 20 experiments) were generated separately for acid or alkali-pretreated CLP using Minitab 16 software for seven variables including four chemical factors (type of moistening agent, and its $\mathrm{pH}$, moisture content, and pretreatment), two physical factors (temperature and incubation time), and one biological factor (inoculum size). Each factor was adjusted at either high level or low level, i.e., temperature $\left(30,35^{\circ} \mathrm{C}\right)$, moistening agent (MSM, YEP), $\mathrm{pH}(5,7)$, moisture content $(50,80 \%)$, inoculum size $\left(0.25,0.5 \mathrm{~mL} \mathrm{~g}^{-1}\right)$, pretreatment (with acid/alkali or untreated), and incubation time (48, $72 \mathrm{~h})$.

After performing experiments, crude enzymes were harvested and assayed for EG, BGL, Xyl, amylase, and pectinase activities, and responses were taken as IU mL $\mathrm{mL}^{-1}$ of the enzymes. The data were analyzed using Minitab 16. After analysis, the most significant factors affecting multienzyme production were identified.

At harvest, $10 \mathrm{~mL}$ of $50 \mathrm{mM}$ sodium citrate buffer $(\mathrm{pH}$ 4.8) containing $0.05 \%(\mathrm{v} / \mathrm{v})$ tween 80 was added to fermented CLP and placed in an orbital shaker at $100 \mathrm{rpm}$ for $1 \mathrm{~h}$. After filtration, CLP was separated and filtrate was centrifuged at $3000 \times g$ for $20 \mathrm{~min}$ and supernatant was taken as crude enzyme preparation.

\section{Enzyme assays}

EG, BGL, Xyl, amylase, and pectinase activities in crude enzyme preparation were assayed by measuring reducing sugars according to Miller (1959) by incubating $25 \mu \mathrm{L}$ of crude enzyme preparation with $25 \mu \mathrm{L}$ of buffered substrates at $35{ }^{\circ} \mathrm{C}$ for $30 \mathrm{~min}$. Carboxymethyl cellulose, salicin, beechwood xylan, starch, and citrus pectin (0.5\% in $50 \mathrm{mM}$ sodium citrate buffer, $\mathrm{pH} 4.8)$ were used as substrate for EG, BGL, Xyl, amylase, and pectinase. The reaction was quenched by boiling the mixture after adding $150 \mu \mathrm{L}$ of dinitrosalicylic acid and chilling on ice for $5 \mathrm{~min}$. The contents were diluted with $720 \mu \mathrm{L}$ of distilled water and $\mathrm{OD}_{540}$ was taken. One unit of enzyme was defined as the amount of enzyme that liberates one micromole of reducing sugars equivalent to glucose or xylose or galacturonic acid in $1 \mathrm{~min}$ under standard assay conditions.

\section{Saccharification}

Different agro-industrial or fruit wastes including Sugarcane bagasse (SB), Banana peels, Mango peels, Apple peels, Orange peels, CLP, and Pomegranate peels were subjected to saccharification by multienzyme preparation, and results were compared with the saccharification of commercially purified substrates, carboxymethyl cellulose (CMC), beechwood xylan, and pectin. Each substrate $(1 \mathrm{~g})$ was transferred to $50 \mathrm{mM}$ sodium citrate buffer $(\mathrm{pH}$ 4.8) containing $0.2 \%$ sodium azide and loaded with multienzyme preparation standardized with $10 \mathrm{IU} \mathrm{mL}^{-1}$ of pectinase. Saccharification was accomplished at $35{ }^{\circ} \mathrm{C}$ with shaking at $100 \mathrm{rpm}$ for 4 days by taking aliquots intermittently and analyzed for the amount of reducing sugars as given earlier (Rehman et al. 2014).

\section{Clarification of orange juice}

The multienzyme preparation was studied for its application to clarify orange juice. Oranges were purchased locally and juice was extracted using manual screw type extractor. The enzyme preparation standardized as $10 \mathrm{IU} \mathrm{mL}{ }^{-1}$ of xylanase was added to $100 \mathrm{~mL}$ of juice and kept for $60 \mathrm{~min}$ at $35^{\circ} \mathrm{C}$ in a water bath. After treatment, the enzyme was denatured by briefly boiling it for $5 \mathrm{~min}$ followed by centrifugation at $4000 \times g$ for 20 to remove pulp. Absorbance of the enzymatically treated juice was taken at $660 \mathrm{~nm}$ and compared with distilled water to calculate percentage transmittance. The viscosity of the juice was measured using Ostwald viscometer at room temperature by taking time of flow into consideration and using the formula as given Nagar et al. (2012).

\section{Results and discussion}

Fruit wastes largely remain under-utilized and hence offer prospect for being used as fermentation raw material. Previously, SSF of Orange peels (Mantzouridou et al. 2015) and Apple pomace (Madrera et al. 2015) has been reported by employing the strains of $S$. cerevisiae, Hanseniaspora valbyensis, and $H$. uvarum, respectively. However, these and similar studies employed one or two strains of the yeasts to obtain one product. The production of multienzyme preparation under SSF of a fruit waste by employing a yeast consortium has not been reported, so far.

Initially, the yeast strains, MK-118, MK-157, and MK-160, were cross streaked on SDA plates; as none of the strains showed any inhibitory effect, and therefore, it was perceived that these strains can be used to develop a consortium. As a first step, various fruit waste materials including peels of Mango, Pomegranate, Apple, 
Sweet Lime (CLP), Banana, and Orange were utilized as a source of carbon under SSF and production of multienzyme was investigated. The results showed that the highest titers of EG (26.64 $\mathrm{IU} \mathrm{mL}^{-1}$ ) were expressed when Mango peels were used as SSF substrate (Table 1). SSF of Banana peels and Apple peels did not produce appreciable amount of enzymes, whereas SSF of Orange peels gave $5.5,7.7$, and $2.3 \mathrm{IU} \mathrm{mL}^{-1}$ of EG, BGL, and Xyl titers, respectively. In comparison, SSF of CLP yielded $9.03 \mathrm{IU} \mathrm{mL}^{-1}$ of EG, 7.4 $\mathrm{IU} \mathrm{mL}^{-1}$ of BGL, and $10.3 \mathrm{IU} \mathrm{mL}^{-1}$ of Xyl. On the basis of highest titers of EG, $\mathrm{BGL}$, and Xyl, CLP was selected for further studies. The utmost possible literature survey did not show any report describing CLP for the production of PCWDEs.

Although, SSF processes using untreated substrates have been reported (Rehman et al. 2014; Naseeb et al. 2015), however, appropriate pretreatment process renders accessibility of fermentable components of waste material to organisms (Deswal et al. 2011) and improves the yield significantly (Qadir et al. 2018). In this context, the utilization of CLP was evaluated after its separate pretreatment with acid and alkali and multienzyme preparation was studied. In addition to pretreatment, seven factors affecting multienzyme production by SSF of acid-pretreated or alkali-pretreated CLP were investigated using two separate PBDs.

\section{Investigation of factors affecting production of multienzyme under SSF of acid-pretreated and alkali-pretreated CLP}

The data obtained after analysis of PBD for SSF of acidtreated CLP indicated that there was $~ 1.5$-fold increase in the titers of individual activities of multienzyme preparation than that of un-optimized experiments. For instance, EG titers as high as $16.48 \mathrm{IU} \mathrm{mL}^{-1}$ (Table 2) were obtained.

Table 1 Production of endoglucanase (EG), $\beta$-glucosidase (BGL) and xylanase (Xyl) by consortium of yeasts under solid-state fermentation (SSF) of some crude substrates

\begin{tabular}{llll}
\hline Lignocellulosic material & \multicolumn{3}{l}{$\begin{array}{l}\text { Enzyme activities } \\
\left(\mathbf{I U} \mathbf{~ m L}^{-1}\right)^{*}\end{array}$} \\
\cline { 2 - 4 } & EG & BGL & Xyl \\
\hline Apple (Malus pumila) peels & 4.14 & 1.50 & 5.20 \\
Banana (Musa acuminate) peels & $1.90^{\mathrm{a}}$ & 2.20 & $1.80^{\mathrm{a}}$ \\
Mosambi (Citrus limetta) peels & 9.00 & 7.40 & 10.30 \\
Mango (Mangifera indica) peels & $26.60^{\mathrm{a}}$ & 0 & 4.40 \\
Orange (Citrus reticulata) peels & 5.50 & 7.70 & $2.30^{\text {a }}$ \\
Pomegranate (Punica granatum) peels & 18.90 & 0 & 0 \\
\hline
\end{tabular}

*The values represent mean of three replicates. The number with alphabet shows a significant standard deviation
Moreover, the factors were screened for their significant effect by analyzing the data and the main effect, regression coefficient, and $T$ and $P$ values of each variable (see Additional file 1: Table S1) were determined. Typically, a lowest $P$ value is associated with higher $T$ value (Pirzadah et al. 2014). The analysis highlighted that the studied factors affected individual activity of the enzymes in multienzyme preparation differently. Moistening agent and inoculum size were found significant for the EG production, while moistening agent alone was significant for the BGL production. Incubation time along with moisture content had a significant role for pectinase production. Amylase production was found significantly influenced by inoculum size, $\mathrm{pH}$, incubation time, and pretreatment of CLP with acid. While none of the factors had significant effect on xylanase production. Previously, Yahya et al. (2016) did not get any significant factor for the production of amylase by $A$. tubingenses SY1 when nine factors were screened using PBD; it was argued that the robustness of the process interferes with the determination of the significant factor.

The significant factors explored in this study have been described for their pivotal role in fermentation process. For instance, inoculum size if kept at low level, affects the cell density drastically, whereas a higher inoculum may yield high cell density, but it results in rapid depletion of nutrient thereby retards the productivity (Yoon et al. 2014). Moistening agent and the level of moisture depend on type of organism and fermentation substrate. In their studies on pectinase production by Pseudozyma sp. under SSF of citrus peels, Sharma et al. (2014) demonstrated that owing to their high contents of fermentable carbohydrates, such materials do not need to be moistened by higher level of moistening agents.

The data obtained after performing experiments as suggested by PBD for alkali-pretreated CLP indicated that the highest titers of EG, BGL, Xyl, amylase, and pectinase were found as 14.75, $18.5 \mathrm{~L}, 18.06,17.86$, and $38.31 \mathrm{IU} \mathrm{mL}^{-1}$ respectively (Table 3 ). It was evaluated that pretreatment was found statistically significant for the production of all the enzymes activities under SSF of alkali-pretreated substrate. For BGL and pectinase, moistening agent and incubation time were also considered as significant factors. Moreover, Xyl and amylase production were significantly influenced by $\mathrm{pH}$ and moistening agent, respectively (see Additional file 1: Table S2).

In general, temperature is regarded as significant environmental factor that affects SSF or SmF, but in the current study, temperature did not show any effect on the production of any enzyme under SSF of CLP. The ability of the strains of $C$. tropicalis used in the consortium to grow under a wide range of temperature may be considered to explain this observation (Shariq and Sohail 2018). 
Table 2 Plackett-Burman for acid-pretreated substrate

\begin{tabular}{|c|c|c|c|c|c|c|c|c|c|c|c|c|}
\hline \multirow[t]{2}{*}{ Run order } & \multicolumn{7}{|c|}{ Experimental parameters } & \multicolumn{5}{|c|}{ Enzyme production $\left(\mathrm{IU} \mathrm{mL}^{-1}\right)^{\mathrm{a}}$} \\
\hline & $\begin{array}{l}\text { Temperature } \\
\left({ }^{\circ} \mathrm{C}\right)\end{array}$ & $\mathrm{pH}$ & $\begin{array}{l}\text { Moistening } \\
\text { agent }\end{array}$ & $\begin{array}{l}\text { Incubation } \\
\text { time (h) }\end{array}$ & $\begin{array}{l}\text { Inoculum } \\
\text { size } \\
\left(\mathrm{mL} \mathrm{g}^{-1}\right)\end{array}$ & $\begin{array}{l}\text { Moisture } \\
\text { content } \\
(\%)\end{array}$ & Pretreatment & EG & BGL & Xyl & PEC & AMY \\
\hline 1 & 30 & 7 & MSM & 48 & 0.25 & 80 & Acid & 5.62 & 8.75 & 8.85 & 12.24 & 3.09 \\
\hline 2 & 35 & 7 & YEP & 48 & 0.25 & 50 & Acid & 7.40 & 11.87 & 14.58 & 3.80 & 6.09 \\
\hline 3 & 35 & 5 & YEP & 72 & 0.25 & 80 & $\mathrm{Nil}$ & 9.22 & 14.85 & 11.12 & 26.46 & 17.86 \\
\hline 4 & 30 & 5 & MSM & 72 & 0.5 & 80 & Acid & 3.95 & 6.09 & 17.02 & 27.09 & 14.07 \\
\hline 5 & 35 & 7 & MSM & 48 & 0.5 & 50 & Acid & 12.54 & 20.25 & 7.10 & 18.41 & 9.79 \\
\hline 6 & 35 & 7 & YEP & 72 & 0.25 & 50 & $\mathrm{Nil}$ & 9.37 & 18.50 & 11.36 & 15.67 & 12.97 \\
\hline 7 & 30 & 7 & YEP & 72 & 0.5 & 80 & $\mathrm{Nil}$ & 10.95 & 15.59 & 12.01 & 18.64 & 17.02 \\
\hline 8 & 30 & 7 & YEP & 48 & 0.5 & 80 & Acid & 11.56 & 13.51 & 3.50 & 10.46 & 6.65 \\
\hline 9 & 35 & 5 & YEP & 48 & 0.25 & 80 & Acid & 12.54 & 10.83 & 3.83 & 10.94 & 2.26 \\
\hline 10 & 35 & 7 & MSM & 72 & 0.25 & 80 & Acid & 11.75 & 11.99 & 18.20 & 15.92 & 8.56 \\
\hline 11 & 35 & 5 & YEP & 72 & 0.5 & 50 & Acid & 16.48 & 15.54 & 25.13 & 6.84 & 25.47 \\
\hline 12 & 35 & 7 & MSM & 72 & 0.5 & 80 & $\mathrm{Nil}$ & 9.66 & 12.62 & 8.88 & 25.56 & 13.42 \\
\hline 13 & 30 & 5 & YEP & 72 & 0.5 & 50 & Acid & 12.57 & 15.00 & 24.67 & 11.21 & 21.37 \\
\hline 14 & 35 & 5 & MSM & 48 & 0.5 & 80 & $\mathrm{Nil}$ & 7.65 & 8.33 & 14.26 & 14.59 & 17.66 \\
\hline 15 & 30 & 5 & MSM & 72 & 0.25 & 50 & Acid & 0 & 11.72 & 16.60 & 5.64 & 14.94 \\
\hline 16 & 35 & 5 & MSM & 48 & 0.5 & 50 & $\mathrm{Nil}$ & 11.84 & 12.48 & 14.65 & 8.83 & 15.58 \\
\hline 17 & 30 & 7 & MSM & 72 & 0.25 & 50 & $\mathrm{Nil}$ & 5.18 & 12.46 & 7.39 & 14.39 & 9.72 \\
\hline 18 & 30 & 7 & YEP & 48 & 0.5 & 50 & Nil & 14.75 & 12.93 & 17.22 & 14.09 & 16.57 \\
\hline 19 & 30 & 5 & YEP & 48 & 0.25 & 80 & $\mathrm{Nil}$ & 12.62 & 13.67 & 18.06 & 14.10 & 16.28 \\
\hline 20 & 30 & 5 & MSM & 48 & 0.25 & 50 & $\mathrm{Nil}$ & 6.01 & 8.53 & 15.09 & 10.40 & 13.42 \\
\hline
\end{tabular}

SSF of acid-pretreated Citrus limetta was carried out by yeast consortium, factors affecting multienzyme PREPARATION were adjusted at two levels (temperature 30 , $35^{\circ} \mathrm{C} ; \mathrm{pH} 5,7$; Moistening agent mineral salt medium or MSM, yeast extract and peptone; incubation time $48,72 \mathrm{~h}$; inoculum size $0.25,0.5 \mathrm{~mL} \mathrm{~g}{ }^{-1}$; moisture content $50,80 \%$; pretreatment acid, no treatment, or nil), and the production of endoglucanase (EG), $\beta$-glucosidase (BGL), xylanase (Xyl), pectinase (PEC), and amylase (AMY) was taken as response

a The values represent average of triplicate with insignificant standard deviation

For further optimization of the enzyme production, one design (either for acid-pretreated CLP, design 1, or alkali-pretreated CLP, design 2) needed to be selected according to the objectives of the study. Two-way analysis of variance (two-way ANOVA) was performed to statistically prove which pretreated substrate is better for multienzyme preparation (see Additional file 1: Table S3). $F$ value and $F$ critical value was correlated to determine any significant difference between the IU $\mathrm{mL}^{-1}$ of the two designs. It was concluded that mean of IU mL $\mathrm{mL}^{-1}$ of the design 2 is greater than design 1 , because $F$ value is greater than $F$ critical value. Furthermore, $P$ value of the model is less than 0.05 which presented a definite significant difference between IU $\mathrm{mL}^{-1}$ of the two designs. Hence, it can be concluded that alkali-pretreated CLP is a better substrate for multienzyme preparation than acid-pretreated CLP. This finding can be linked with the studies conducted by Qadir et al. (2018) where damaging effect of alkaline pretreatment on sugarcane bagasse was more pronounced than that of acidic pretreatment; consequently, fermentation of alkali-pretreated substrate yielded more enzymes. Therefore, in this study, RSM was performed for the optimization of factors affecting multienzyme preparation under SSF of alkali-pretreated CLP.

\section{Optimization of multienzyme preparation by yeast} consortium under SSF of alkali-pretreated CLP using BoxBehnken design

Although, PBD offers useful observation about the variable's effects on a response, however, it does not provide actual values of every variable used optimally in a process. Therefore, BBD was employed to examine the interactive effect of factors on EG, BGL, and Xyl production, and to determine optimal value of each variable. Four significant variables, i.e., incubation time, moistening agent, pretreatment, and $\mathrm{pH}$, were studied. Pectinase and amylase production was also analyzed. Temperature, inoculum size, and moisture content (factors other than significant) were adjusted at $30{ }^{\circ} \mathrm{C}, 500 \mu \mathrm{L} \mathrm{g}^{-1}$, and $80 \%$, respectively. A BBD design consisted of 27 experiments was generated with four variables (at three levels: $-1,0$, 
Table 3 Plackett-Burman for alkali-pretreated substrate

\begin{tabular}{|c|c|c|c|c|c|c|c|c|c|c|c|c|}
\hline \multirow[t]{2}{*}{ Run order } & \multicolumn{7}{|c|}{ Experimental parameters } & \multicolumn{5}{|c|}{ Enzyme production (IU/ML) $^{\mathrm{a}}$} \\
\hline & $\begin{array}{l}\text { Temperature } \\
\left({ }^{\circ} \mathrm{C}\right)\end{array}$ & $\mathrm{pH}$ & $\begin{array}{l}\text { Moistening } \\
\text { agent }\end{array}$ & $\begin{array}{l}\text { Incubation } \\
\text { time }\end{array}$ & $\begin{array}{l}\text { Inoculum } \\
\text { size } \\
\left(\mathrm{mL} \mathrm{g}^{-1}\right)\end{array}$ & $\begin{array}{l}\text { Moisture } \\
\text { content } \\
(\%)\end{array}$ & Pretreatment & EG & BGL & Xyl & PEC & AMY \\
\hline 1 & 30 & 7 & MSM & 48 & 0.25 & 80 & Alk & 2.56 & 2.76 & 4.62 & 18.09 & 3.89 \\
\hline 2 & 35 & 7 & YEP & 48 & 0.25 & 50 & Alk & 5.32 & 4.48 & 8.64 & 20.76 & 9.37 \\
\hline 3 & 35 & 5 & YEP & 72 & 0.25 & 80 & Nil & 9.22 & 14.84 & 11.12 & 26.47 & 17.86 \\
\hline 4 & 30 & 5 & MSM & 72 & 0.5 & 80 & Alk & 4.04 & 5.67 & 7.87 & 38.31 & 4.54 \\
\hline 5 & 35 & 7 & MSM & 48 & 0.5 & 50 & Alk & 4.04 & 5.67 & 7.57 & 13.81 & 4.63 \\
\hline 6 & 35 & 7 & YEP & 72 & 0.25 & 50 & $\mathrm{Nil}$ & 9.37 & 18.5 & 11.36 & 15.67 & 12.97 \\
\hline 7 & 30 & 7 & YEP & 72 & 0.5 & 80 & $\mathrm{Nil}$ & 10.95 & 15.59 & 12.01 & 18.64 & 17.02 \\
\hline 8 & 30 & 7 & YEP & 48 & 0.5 & 80 & Alk & 3.79 & 4.54 & 6.44 & 21.57 & 7.30 \\
\hline 9 & 35 & 5 & YEP & 48 & 0.25 & 80 & Alk & 3.25 & 4.73 & 5.97 & 26.38 & 5.56 \\
\hline 10 & 35 & 7 & MSM & 72 & 0.25 & 80 & Alk & 6.80 & 8.39 & 10.47 & 17.74 & 4.83 \\
\hline 11 & 35 & 5 & YEP & 72 & 0.5 & 50 & Alk & 6.75 & 9.52 & 15.26 & 23.26 & 8.09 \\
\hline 12 & 35 & 7 & MSM & 72 & 0.5 & 80 & Nil & 9.66 & 12.63 & 8.88 & 25.56 & 13.41 \\
\hline 13 & 30 & 5 & YEP & 72 & 0.5 & 50 & Alk & 5.87 & 7.31 & 14.55 & 30.83 & 6.26 \\
\hline 14 & 35 & 5 & MSM & 48 & 0.5 & 80 & Nil & 7.64 & 8.34 & 14.26 & 14.59 & 17.66 \\
\hline 15 & 30 & 5 & MSM & 72 & 0.25 & 50 & Alk & 6.46 & 8.38 & 15.42 & 26.64 & 7.99 \\
\hline 16 & 35 & 5 & MSM & 48 & 0.5 & 50 & Nil & 11.84 & 12.48 & 14.65 & 8.84 & 15.59 \\
\hline 17 & 30 & 7 & MSM & 72 & 0.25 & 50 & $\mathrm{Nil}$ & 5.18 & 12.45 & 7.392 & 14.40 & 9.72 \\
\hline 18 & 30 & 7 & YEP & 48 & 0.5 & 50 & $\mathrm{Nil}$ & 14.75 & 12.92 & 17.22 & 14.10 & 16.58 \\
\hline 19 & 30 & 5 & YEP & 48 & 0.25 & 80 & Nil & 12.62 & 13.67 & 18.06 & 14.10 & 16.28 \\
\hline 20 & 30 & 5 & MSM & 48 & 0.25 & 50 & $\mathrm{Nil}$ & 6.01 & 8.53 & 15.10 & 10.40 & 13.42 \\
\hline
\end{tabular}

SSF of acid-pretreated Citrus limetta was carried out by yeast consortium, factors affecting multienzyme preparation were adjusted at two levels (temperature 30 , $35^{\circ} \mathrm{C} ; \mathrm{pH} 5,7$; moistening agent mineral salt medium or MSM, yeast extract and peptone; incubation time $48,72 \mathrm{~h}$; inoculum size $0.25,0.5 \mathrm{~mL} \mathrm{~g} \mathrm{~g}^{-1}$; moisture content $50,80 \%$; pretreatment acid, no treatment, or nil), and production of endoglucanase (EG), $\beta$-glucosidase (BGL), xylanase (Xyl), pectinase (PEC), and amylase (AMY) was taken as response

a The values represent average of triplicate with insignificant standard deviation

$+1)$. The design matrix of the variables together with the experimental responses is shown in Table 4.

The response of experimental runs of EG, BGL, XYL, amylase, and pectinase activities varied from 0.96 to $13.30,0.888$ to $16.5,4$ to $15.67,0.917$ to 14.01 , and 21.944 to $32.06 \mathrm{IU} \mathrm{mL}^{-1}$, respectively (Table 4). Experiment number 20 and 22 showed highest protein titer, i.e., 22.75 and $22.5 \mathrm{mg} \mathrm{mL}^{-1}$, while experiment number 9 and
11 gave lowest protein titer, i.e., $11 \mathrm{mg} \mathrm{mL}^{-1}$ (data not shown). It was observed that production of the enzymes was lower than compared to the activities obtained during PBD, but BBD offers an exact value of each significant factor, and hence, this is proven as cost-effective method.

Additionally, the regression coefficient equations were calculated and production of EG, BGL, Xyl, and amylase was expressed as the second-order polynomial equations:

$$
\begin{aligned}
\text { EG activity }(\mathrm{IU} \mathrm{mL} & -1)= \\
& +26.7-127.3 A-0.125 B-23.60 C+1.07 D \\
& +11.35 A C+0.43 A D+0.0050 B C+0.0052 B D+0.431 C D
\end{aligned}
$$

$$
\begin{aligned}
\operatorname{BGL} \text { activity }\left(\mathrm{IU} \mathrm{mL}^{-1}\right)= & -15.5-54.7 A+0.539 B+15.1 C-26.25 D \\
& +79.6 A^{2}-0.00308 B^{2}-0.941 C^{2}+0.423 D^{2}-0.260 A B \\
& -12.00 A C+6.57 A D+0.0089 B C+0.0518 B D+3.01 C D
\end{aligned}
$$


Table 4 Box-Behnken design matrix for production of endoglucanase (EG), $\beta$-glucosidase (BGL), xylanase (Xyl), pectinase (PEC), and amylase (AMY) under SSF of Citrus limetta peels (CLP) by the yeast consortium

\begin{tabular}{|c|c|c|c|c|c|c|c|c|c|}
\hline \multirow[t]{2}{*}{ Run order } & \multicolumn{4}{|c|}{ Experimental parameters } & \multicolumn{5}{|c|}{ Enzyme production $\left(\mathrm{IU} \mathrm{mL}^{-1}\right)^{\mathrm{a}}$} \\
\hline & Alkali (\%) & $\begin{array}{l}\text { Incubation time } \\
\text { (h) }\end{array}$ & $\mathrm{pH}$ & Moistening agent & EG & BGL & $\mathrm{XYL}$ & AMY & PEC \\
\hline 1 & 0.5 & 48 & 6 & $M S M+Y E$ & 8.86 & 10.37 & 12.38 & 7.12 & 31.34 \\
\hline 2 & 1 & 48 & 6 & $M S M+Y E$ & 1.97 & 5.54 & 5.98 & 6.65 & 31.23 \\
\hline 3 & 0.5 & 96 & 6 & $M S M+Y E$ & 8.72 & 16.5 & 12.51 & 7.18 & 30.42 \\
\hline 4 & 1 & 96 & 6 & $M S M+Y E$ & 4.36 & 5.42 & 8.69 & 6.28 & 22.64 \\
\hline 5 & 0.75 & 72 & 5 & MSM & 3.64 & 2.85 & 5.36 & 4.41 & 21.10 \\
\hline 6 & 0.75 & 72 & 7 & MSM & 4.12 & 3.43 & 6.67 & 7.97 & 26.39 \\
\hline 7 & 0.75 & 72 & 5 & YEP & 3.76 & 2.04 & 5.35 & 3.89 & 21.94 \\
\hline 8 & 0.75 & 72 & 7 & YEP & 5.96 & 14.65 & 5.5 & 10.56 & 30.73 \\
\hline 9 & 0.5 & 72 & 6 & MSM & 5.7 & 13.12 & 15.67 & 14.02 & 29.42 \\
\hline 10 & 1 & 72 & 6 & MSM & 1.24 & 3.84 & 6.41 & 9.92 & 26.49 \\
\hline 11 & 0.5 & 72 & 6 & YEP & 6.40 & 15.62 & 5.56 & 10.26 & 34.39 \\
\hline 12 & 1 & 72 & 6 & YEP & 2.37 & 12.91 & 10.74 & 9.74 & 32.6 \\
\hline 13 & 0.75 & 48 & 5 & $M S M+Y E$ & 2.82 & 0.888 & 7.09 & 2.26 & 25.41 \\
\hline 14 & 0.75 & 96 & 5 & $M S M+Y E$ & 4.467 & 4.24 & 3.56 & 0.92 & 24.79 \\
\hline 15 & 0.75 & 48 & 7 & $M S M+Y E$ & 4.54 & 1.85 & 4.0 & 1.57 & 24.88 \\
\hline 16 & 0.75 & 96 & 7 & $M S M+Y E$ & 6.68 & 6.06 & 6.22 & 6.22 & 28.92 \\
\hline 17 & 0.5 & 72 & 5 & $M S M+Y E$ & 13.30 & 9.09 & 13.71 & 12.94 & 23.19 \\
\hline 18 & 1 & 72 & 5 & $M S M+Y E$ & 0.92 & 9.56 & 9.14 & 3.67 & 30.77 \\
\hline 19 & 0.5 & 72 & 7 & $M S M+Y E$ & 7.57 & 15.71 & 11.15 & 11.69 & 27.51 \\
\hline 20 & 1 & 72 & 7 & $M S M+Y E$ & 6.53 & 4.17 & 6.28 & 10.14 & 27.51 \\
\hline 21 & 0.75 & 48 & 6 & MSM & 2.09 & 3.87 & 4.56 & 1.65 & 22.64 \\
\hline 22 & 0.75 & 96 & 6 & MSM & 4.15 & 2.77 & 5.64 & 3.29 & 24.53 \\
\hline 23 & 0.75 & 48 & 6 & YEP & 2.42 & 3.24 & 5.86 & 4.13 & 20.61 \\
\hline 24 & 0.75 & 96 & 6 & YEP & 4.98 & 7.12 & 4.97 & 4.04 & 30.57 \\
\hline 25 & 0.75 & 72 & 6 & $M S M+Y E$ & 2.91 & 6.78 & 6.33 & 7.96 & 32.07 \\
\hline 26 & 0.75 & 72 & 6 & $M S M+Y E$ & 5.34 & 2.78 & 6.40 & 6.82 & 28.34 \\
\hline 27 & 0.75 & 72 & 6 & $M S M+Y E$ & 3.37 & 8.27 & 7.99 & 7.11 & 27.42 \\
\hline
\end{tabular}

Alkali pretreatment to CLP was given using $0.5,0.75$ or $1 \% \mathrm{NaOH}$, incubation time varied 48,72 , or $96 \mathrm{~h}$, pH adjusted to 5,6 , or 7 , and moistening agent was used mineral salt medium (MSM) or yeast extract (YE) or both (MSM+YE)

a The values represent average of triplicate with insignificant standard deviation

$$
\begin{aligned}
& \mathrm{Xyl}(\mathrm{IU} \mathrm{mL} \\
&-1)= 62.6-131.5 A-0.169 B+3.02 C-4.98 D+59.13 A^{2} \\
&-0.00156 B^{2}-0.575 C^{2}-0.794 D^{2}+0.108 A B-0.30 A C \\
&+14.44 A D+0.0599 B C-0.0205 B D-0.288 C D
\end{aligned}
$$

$$
\begin{aligned}
\text { Amylase }\left(\mathrm{IU} \mathrm{mL} \mathrm{m}^{-1}\right)= & 39.4-138.4 A+0.672 B-0.49 C-6.53 D+53.8 A^{2} \\
& -0.00681 B^{2}-0.806 C^{2}+0.150 D^{2}-0.018 A B+7.72 A C \\
& +3.57 A D+0.0624 B C-0.0181 B D+0.778 C D,
\end{aligned}
$$

where $A, B, C$, and $D$ represent coded values for pretreatment, incubation time, $\mathrm{pH}$, and moistening agent, respectively.
The EG, BGL, Xyl, amylase, and pectinase responses were analyzed through BBD which generated ANOVA for each enzyme that revealed that the model was 
significant (see Additional file 1: Table S4) as indicated by $F$ value of $12.66,39.259,9.22$, and 9.80 , respectively, and small $P$ value of the model (i.e., $<0.05$ ). $R^{2}$ values for EG, BGL, Xyl, and amylase were $92.67 \%, 91.92 \%, 91.49 \%$, and $91.96 \%$, respectively, represent that the model can demonstrate above indicated percentages of total variation, and hence, the models for EG, BGL, Xyl, and amylase have good correspondence with the experimental data (Salihu et al. 2011; Cui and Zhao 2012).

The contour plots and response surface plots were used for predicting enhanced production by anticipating the optimal values of different variables. According to the analysis of results obtained, it can be speculated that pretreatment with $0.5 \% \mathrm{NaOH}$ and moistening agent $2(\mathrm{MSM}+\mathrm{YE})$ can be used to get more titers of EG (Fig. 1a, b). Additional file 1: Fig. S1a, b presents that $0.5 \% \mathrm{NaOH}$-pretreated substrate with moistening agent's pH 6.7 is the best combination for EG production. This finding was in agreement with Rahnama et al. (2013), where $0.5 \%$ alkali-pretreated substrate was found a better substrate for cellulase and xylanase production by Trichoderma harzianum SNRS3 under SSF. Neutral pH was reported as optimal pH by Hmad et al. (2014) for the production of cellulase from filamentous fungus Stachybotrys microspora (mutant strain A19). The analysis of data revealed that there was an enhanced production of EG with an increase in the incubation time and $0.5 \% \mathrm{NaOH}$-pretreated substrate (Fig. 1c); however, a decline in EG production was observed upon further increase in $\mathrm{NaOH}$ (see Additional file 1: Fig. S1c). This can be explained as enzyme production reaches to maximum in log phase of the growth, and this finding was in agreement by Rosyida et al. (2015).

For the production of BGL, two factors $\mathrm{NaOH}$ pretreatment and moistening agent interacted in a way that under SSF of $0.5 \% \mathrm{NaOH}$-pretreated substrate moistened with YEP, consortium of yeasts gave enhanced titer of BGL, while incubation time and $\mathrm{pH}$ were kept constant (Fig. 2a). However, BGL production was adversely affected with an increase in the amount of $\mathrm{NaOH}$ for pretreatment (see Additional file 1: Fig. S2a). There was no significant relationship between $\mathrm{pH}$ and pretreatment variables (see Fig. 2b; Additional file 1: Fig. S2b), while, when $0.5 \% \mathrm{NaOH}$ pretreatment was compared with incubation time, plot showed that $80 \mathrm{~h}$ and above incubation time with $0.5 \% \mathrm{NaOH}$-pretreated substrate were considered as a better combination (Fig. 2c, Additional file 1: Fig. S2c). Brijwani et al. (2010) demonstrated maximum filter paperase activity of $10.7 \mathrm{FPU}$ gds $^{-1}$ and $\beta$-glucosidase of 10.7 IU gds ${ }^{-1}$ within $96 \mathrm{~h}$ incubation time under SSF of wheat bran with optimized conditions of temperature at $30{ }^{\circ} \mathrm{C}, \mathrm{pH}$ of growth medium 7 and $70 \%$ moisture content.
YEP (moistening agent 3) with $\mathrm{pH}$ above 6 and more than $70 \mathrm{~h}$ incubation time showed best combination for BGL production (Fig. 2). Suwannarangsee et al. (2014) studied that yeast extract and initial $\mathrm{pH}$ of media had pronounced effect on the production of cell wall degrading enzymes by Aspergillus aculeatus BCC199.

The data further demonstrated that enhanced production of Xyl can be achieved using CLP treated with 0.5\% $\mathrm{NaOH}$ moistened with MSM while keeping incubation time and moistening agent's pH constant (Fig. 3). A decline in production of Xyl was observed with moistening agents other than MSM and increase in the amount of $\mathrm{NaOH}$ for pretreatment purpose (see Additional file 1: Fig. S3a). Whereas, pH 5-6.5 was found appropriate if the cultivation was carried out until $85 \mathrm{~h}$. Earlier, SSF of wheat bran for $72 \mathrm{~h}$ by Aspergillus fischeri was found appropriate for the production of cellulase free xylanase with the initial medium $\mathrm{pH} 9$ (Tariq et al. 2018). However, in the present study, increase in incubation time and media $\mathrm{pH}$ revealed decreased Xyl production (see Additional file 1: Fig. S3f).

Likewise, moistening agent's $\mathrm{pH}$ and pretreatment with alkali were the most promising factors for the production of amylase by the yeast consortium (Fig. 4). Indeed, pretreatment with $0.5 \%$ alkali and moistening with MSM with $\mathrm{pH}$ ranged 6.5-7 appeared as suitable combinations for the production of amylase (see Additional file 1: Fig. S4).Whereas, under given conditions, incubation time of $58-90 \mathrm{~h}$ was deduced as good condition for the said enzyme production.

To summarize, the optimum levels of the factors were: $\mathrm{NaOH}$ pretreatment $0.5 \%$, incubation time $72 \mathrm{~h}, \mathrm{MSM}$ as moistening agent with $\mathrm{pH} 5$ for EG, BGL, Xyl, and amylase. Under optimized conditions, the maximum activity of EG, BGL, Xyl, and amylase was predicted by the model as $10.93,11.67,15.40$, and $13.23 \mathrm{IU} \mathrm{mL}^{-1}$, respectively. Confirmation experiments were performed, and titers of EG, BGL, Xyl, and amylase were obtained as 9.56, 11.84, 15.09 , and $12.32 \mathrm{IU} \mathrm{mL}^{-1}$ (see Additional file 1: Table S5). The titers of EG obtained were similar to those were obtained by Qadir et al. (2018) from a yeast co-culture using sugarcane bagasse as substrate. However, the cost of CLP would apparently be much lower than that of sugarcane bagasse and, hence, provides a merit to study this consortium further.

The model was declared as insignificant for pectinase production according to ANOVA evaluation as determined by large $P$ value, i.e., 0.373 (see Additional file 1: Table S6) and lower $R^{2}$ value (58.57\%). Therefore, pectinase production was not correlated with the change in variables.

Nonetheless, CLP appeared as promising substrate for the production of multienzyme preparation; 
a

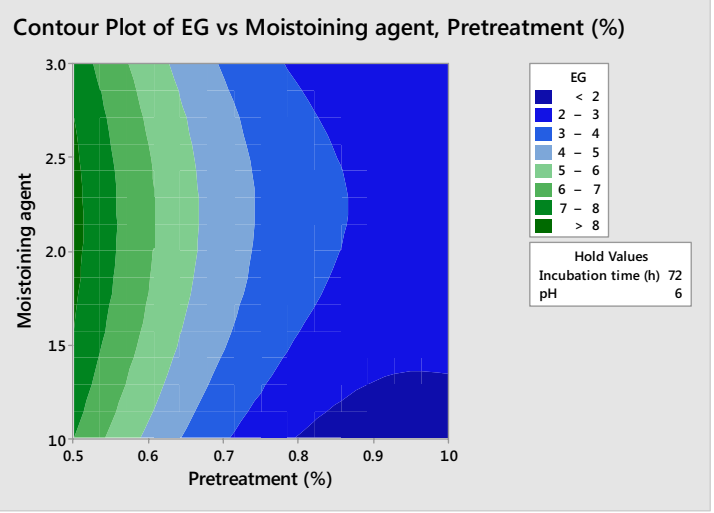

b

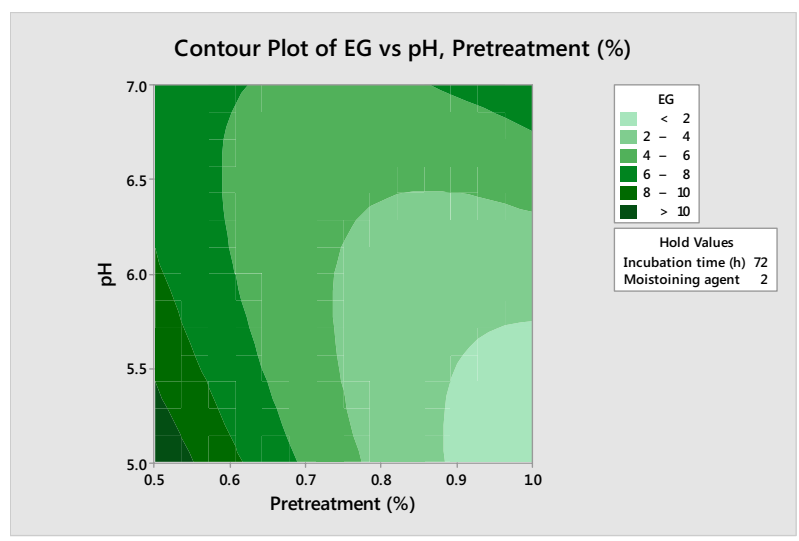

C

Contour Plot of EG vs Incubation time (h), Pretreatment (\%)

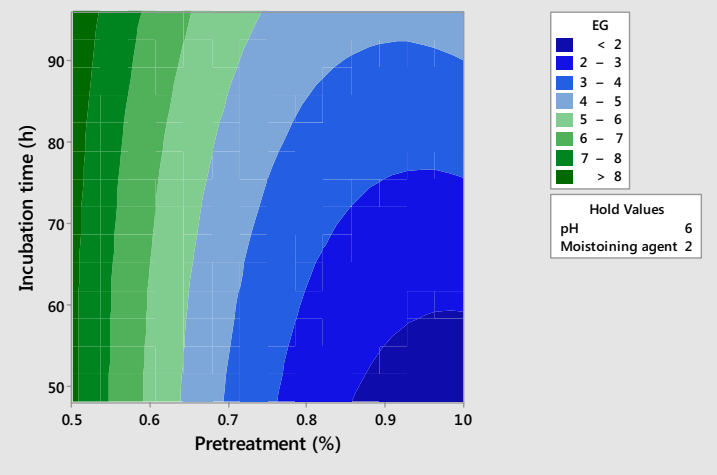

d

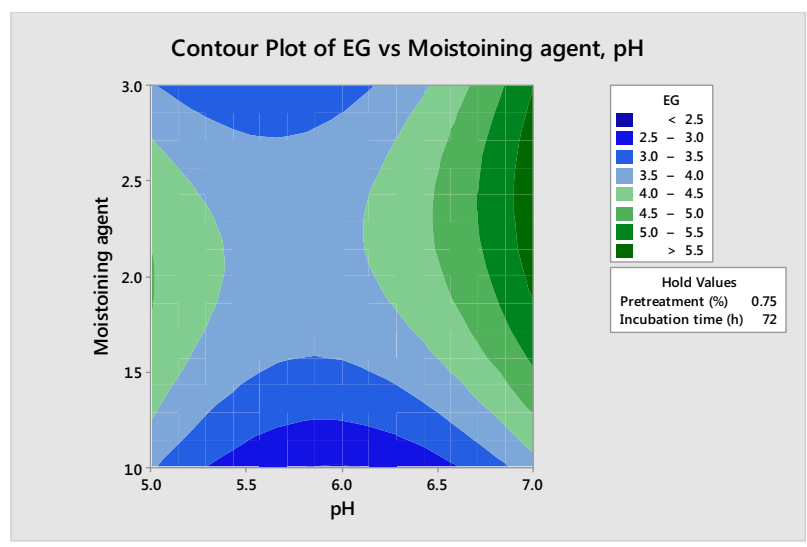

e

Contour Plot of EG vs Moistoining agent, Incubation time (h)
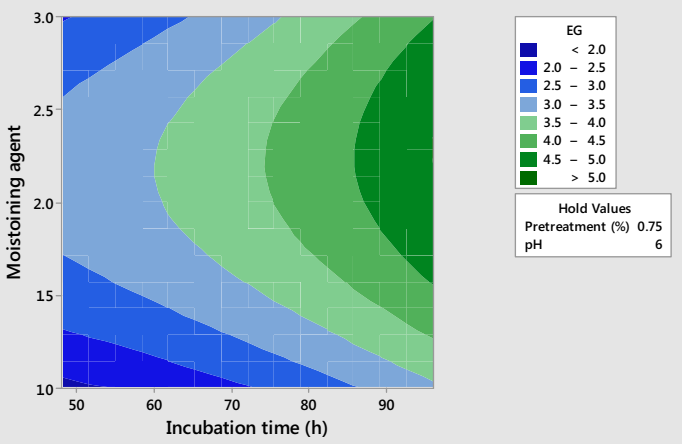

f

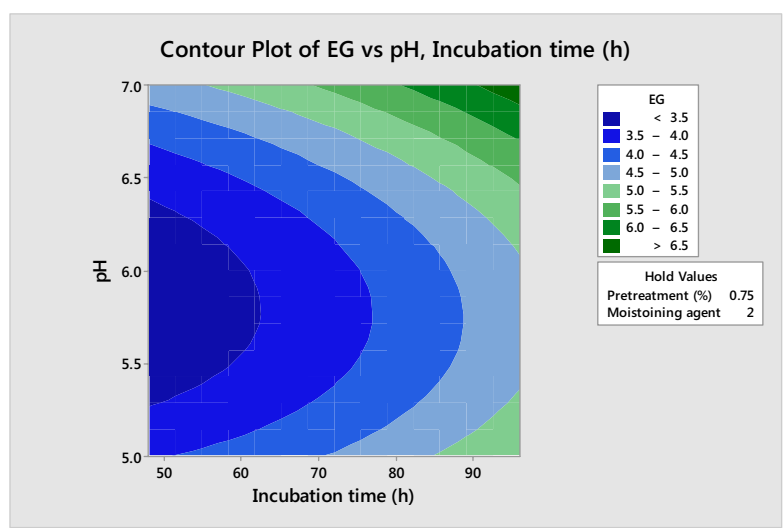

Fig. 1 Contour plots of EG showing interaction between: a moistening agent and pretreatment, $\mathbf{b}$ moistening agent's $\mathrm{pH}$ and pretreatment, $\mathbf{c}$ incubation time and pretreatment, $\mathbf{d}$ moistening agent and its $\mathrm{pH}$, e moistening agent and incubation time, and $\mathbf{f}$ moistening agent's $\mathrm{pH}$ and incubation time

however, technoeconomic assessment is needed prior to reveal feasibility of large-scale production as various factors impede exploitation of such substrates at commercial level as discussed by (Chew et al. 2017). Moreover, the extraction of any other enzyme of interest from fermented CLP (Arshad et al. 2014) through 
a

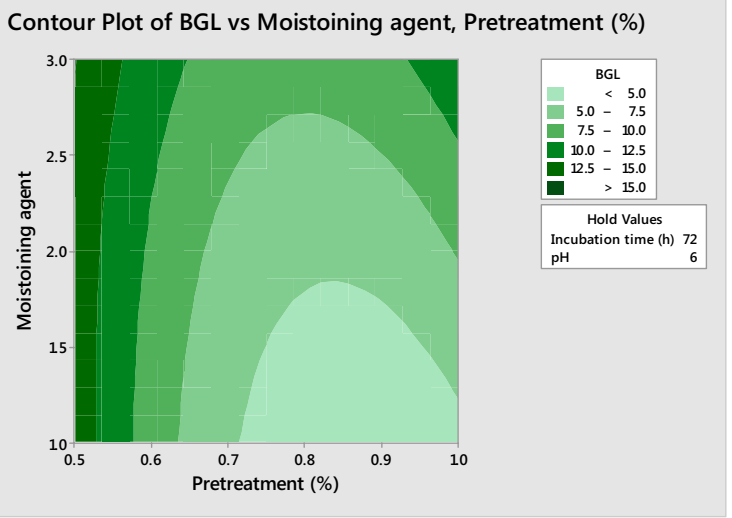

b

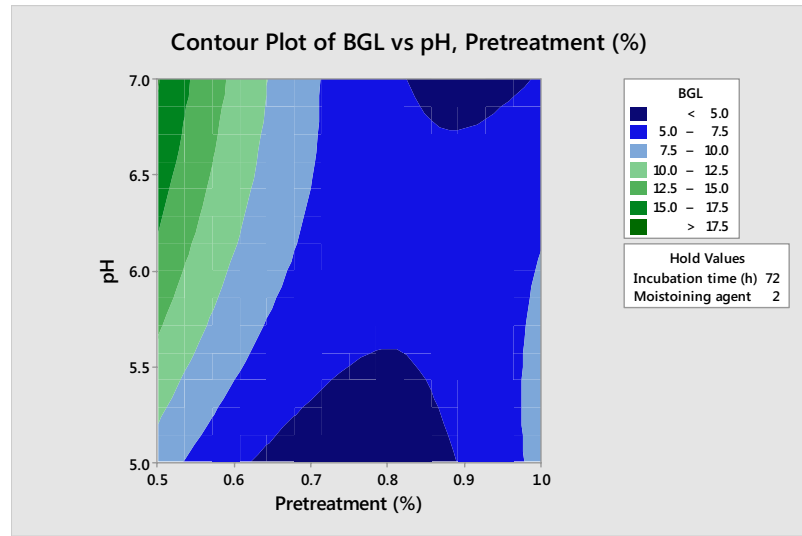

C

Contour Plot of BGL vs Incubation time (h), Pretreatment (\%)

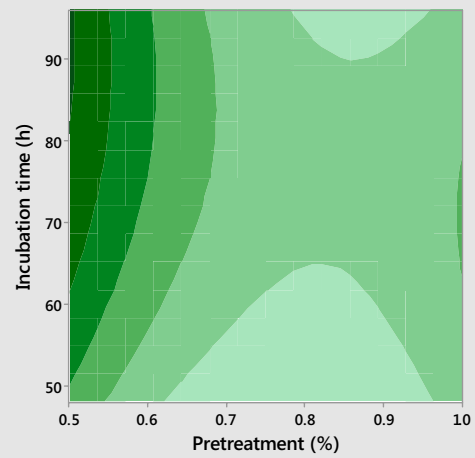

d

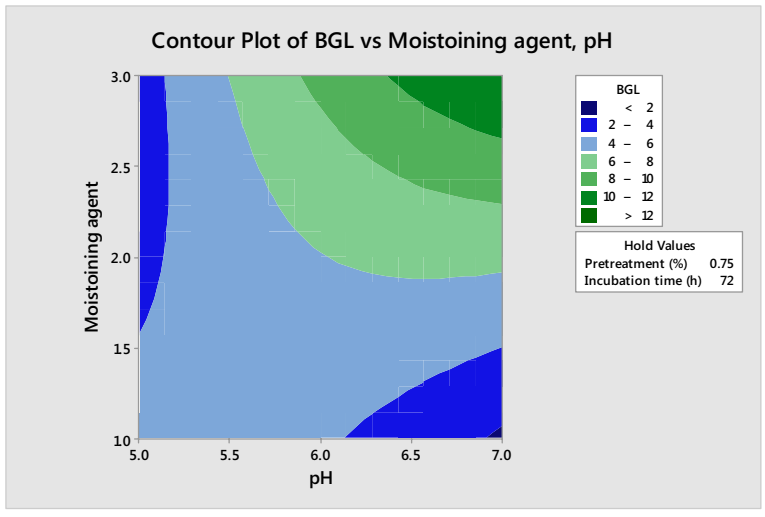

e

Contour Plot of BGL vs Moistoining agent, Incubation time (h)
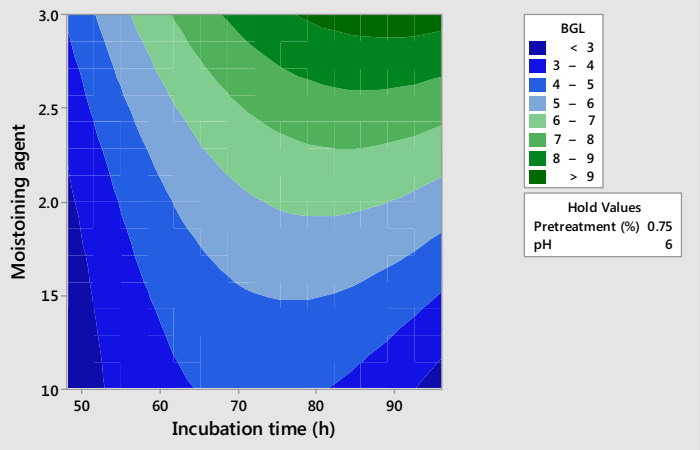

f

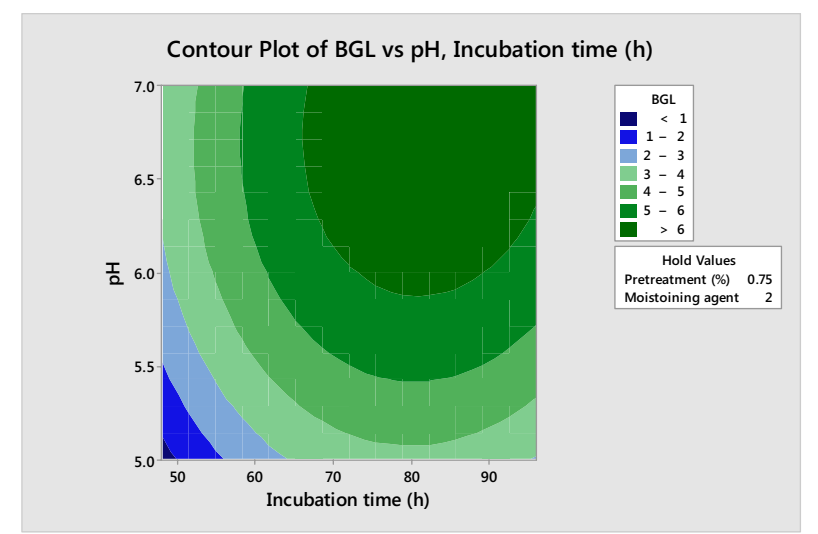

Fig. 2 Contour plots of BGL showing interaction between: a moistening agent and pretreatment, $\mathbf{b}$ moistening agent's pH and pretreatment, c incubation time and pretreatment, $\mathbf{d}$ moistening agent and it's $\mathrm{pH}$, e moistening agent and incubation time, and $\mathbf{f}$ moistening agent's $\mathrm{pH}$ and incubation time 
a

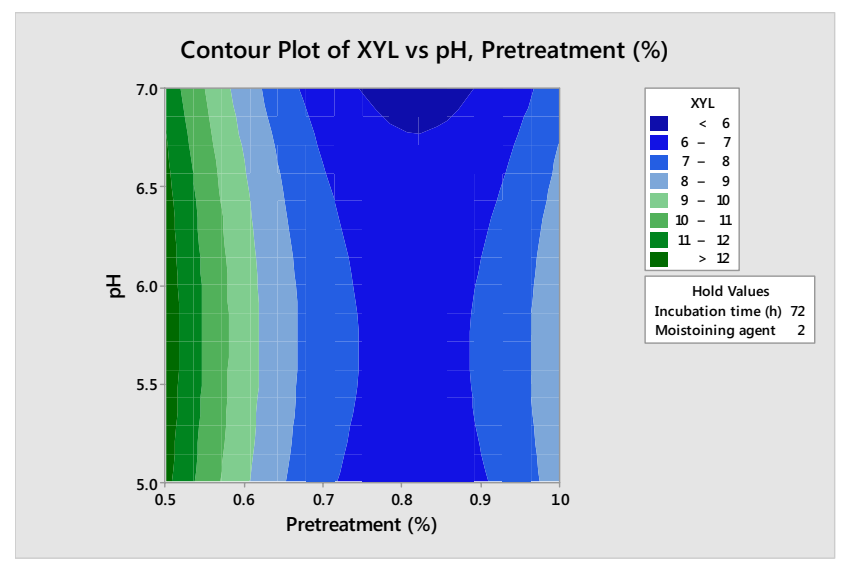

b

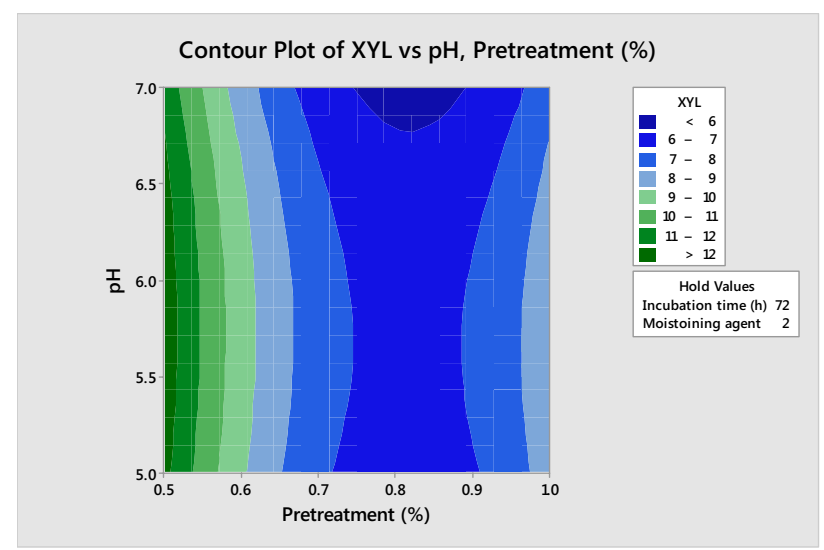

C

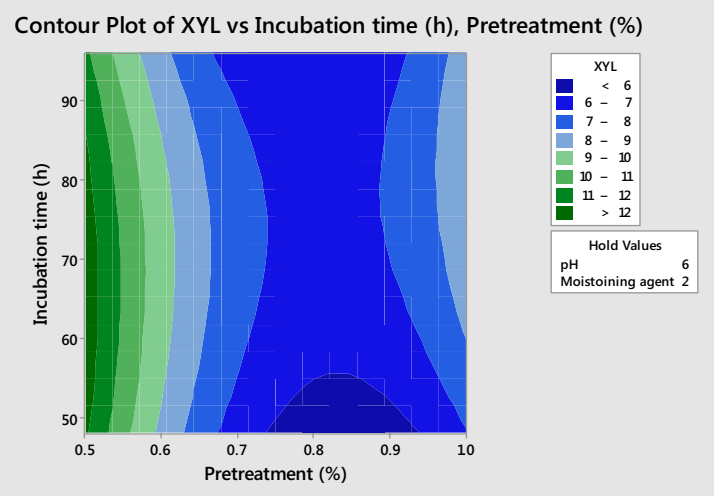

d

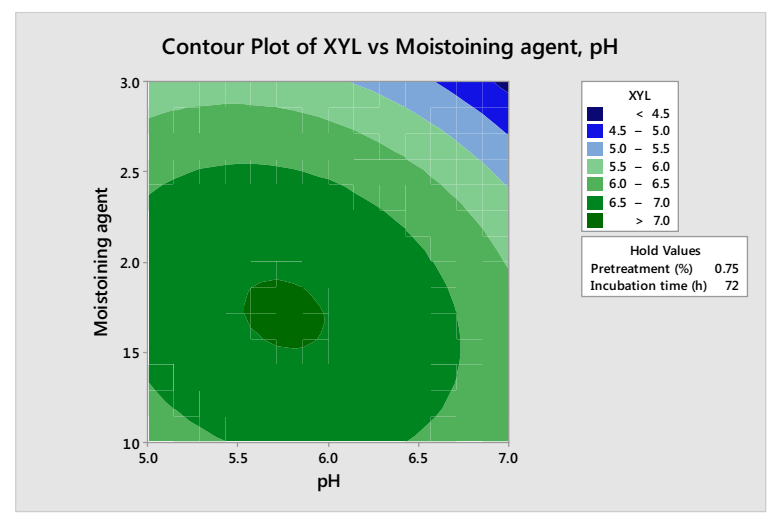

e

Contour Plot of XYL vs Moistoining agent, Incubation time (h)
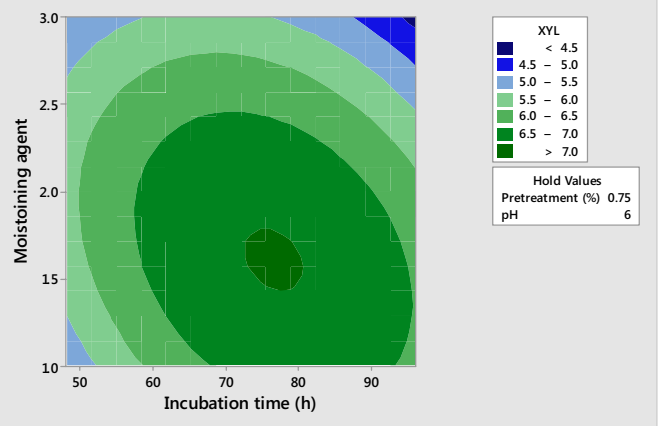

$\mathbf{f}$

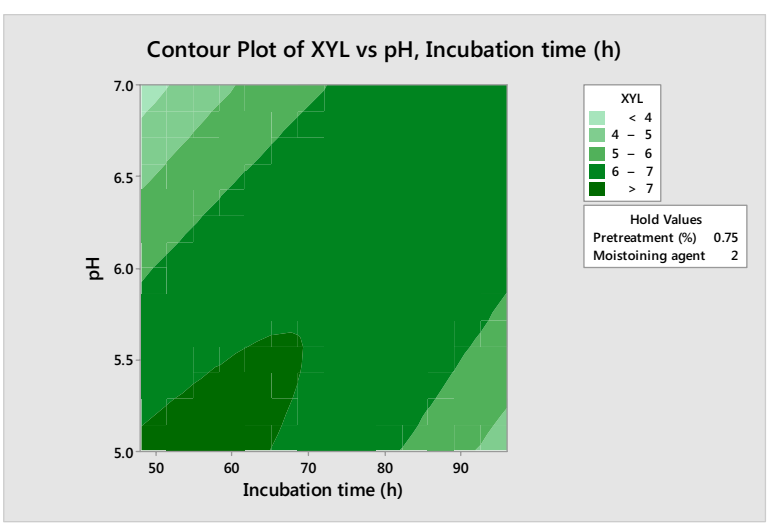

Fig. 3 Contour plots of XYL showing relationship between a moistening agent and pretreatment, $\mathbf{b}$ moistening agent's pH and pretreatment, c incubation time and pretreatment, $\mathbf{d}$ moistening agent and its $\mathrm{pH}, \mathbf{e}$ moistening agent and incubation time, and $\mathbf{f}$ moistening agent's $\mathrm{pH}$ and incubation time

recently developed reverse micelle technology (Sankaran et al. 2019) or any other method that will aid to extend the product range, and hence, the cost can further be reduced.

\section{Saccharification of crude substrates by the multienzyme preparation}

The multienzyme preparation produced by the yeast consortium was evaluated for its ability to be utilized for 
a

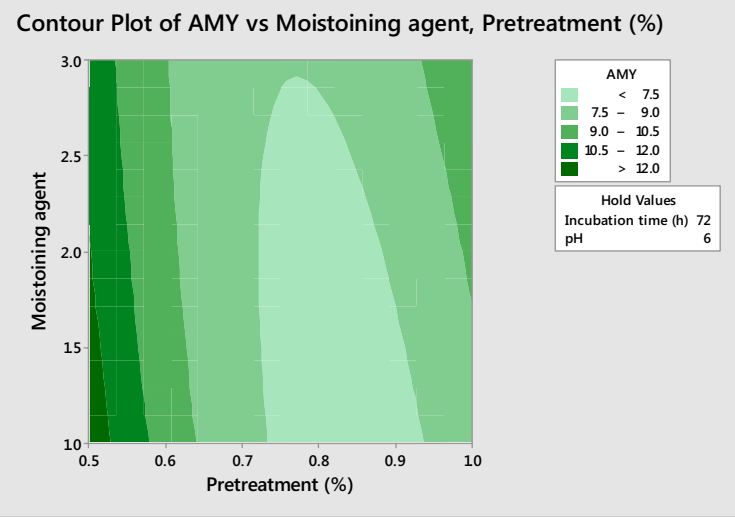

b

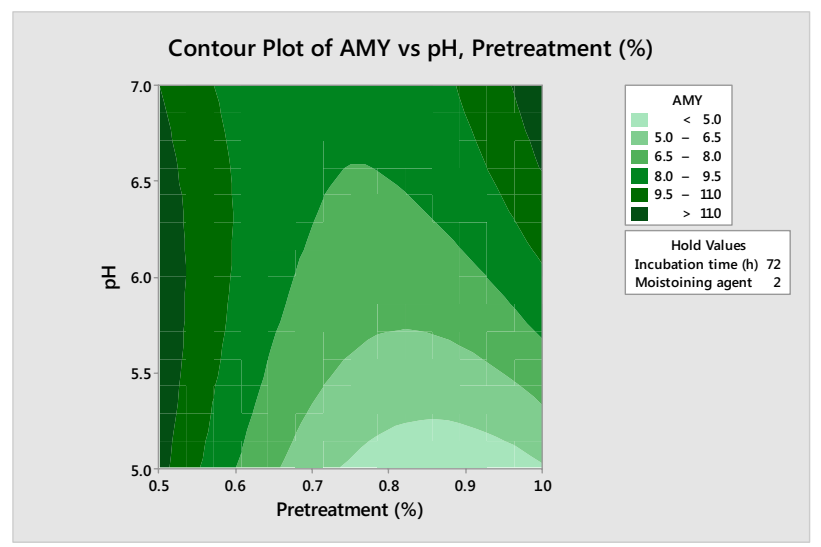

C

Contour Plot of AMY vs Incubation time (h), Pretreatment (\%)

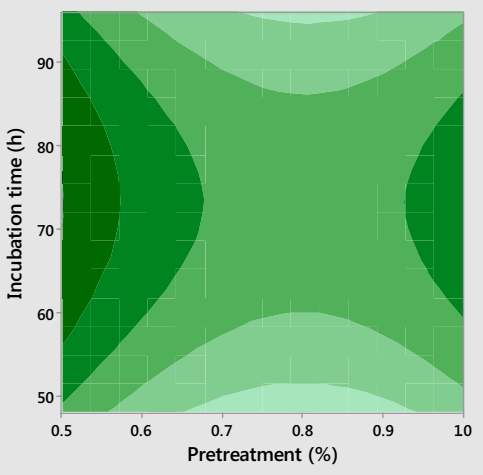

d

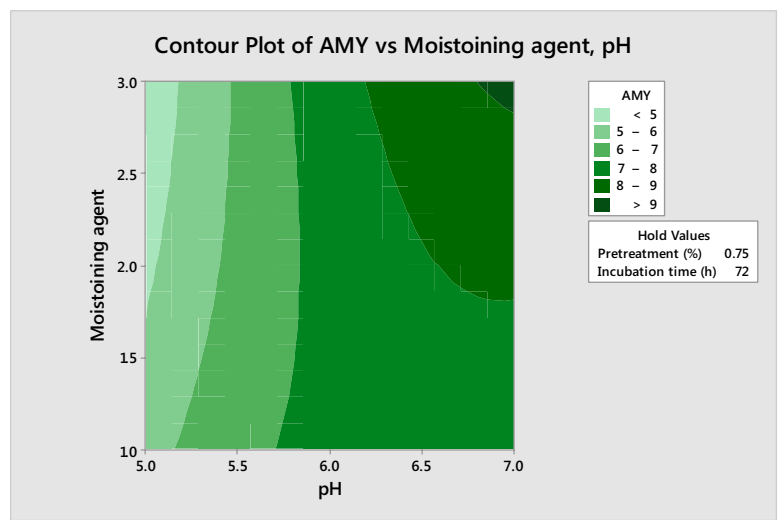

e

Contour Plot of AMY vs Moistoining agent, Incubation time (h)
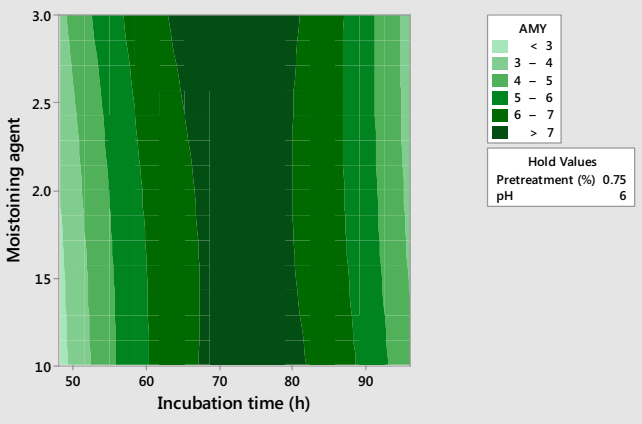

$\mathbf{f}$

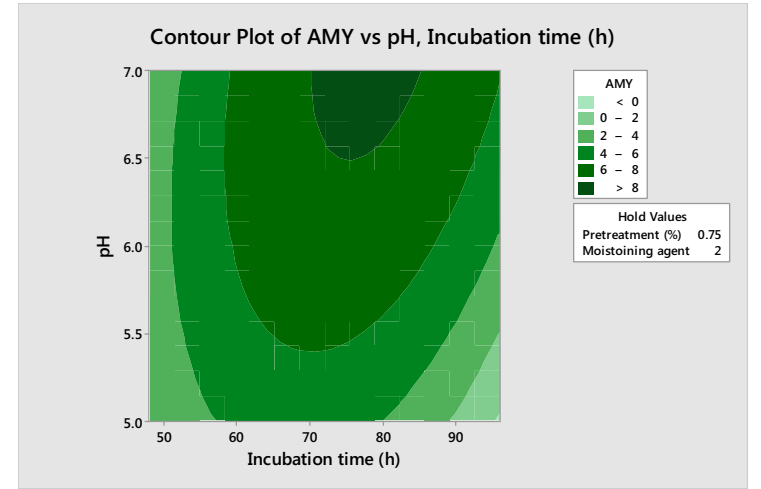

Fig. 4 Contour plots of AMY showing relationship between a moistening agent and pretreatment, $\mathbf{b}$ moistening agent's pH and pretreatment, $\mathbf{c}$ incubation time and pretreatment, $\mathbf{d}$ moistening agent and it's $\mathrm{pH}$, e moistening agent and incubation time, and $\mathbf{f}$ moistening agent's $\mathrm{pH}$ and incubation time

the saccharification of crude substrates, particularly fruit peels. Since, the crude substrate vary in their compositions, therefore, the multienzyme preparation was standardized for pectinase, xylanase, or cellulase preparation considering the major constituent of the substrate. The data demonstrated that when the multienzyme preparation (standardized at $10 \mathrm{IU} \mathrm{mL}^{-1}$ of pectinase) from the yeast consortium was applied to hydrolyze untreated 
peels of Sweet Lime, Pomegranate, Apple, and Orange, it produced reducing sugars at the rate of $2.56,1.23,1.47$, and $1.57 \mathrm{mg} \mathrm{mL}^{-1} \mathrm{~h}^{-1}$, respectively. In the same manner, the preparation standardized with xylanase hydrolyzed Mango peels and Banana peels at the rate of 0.433 and $0.2 \mathrm{mg} \mathrm{mL}^{-1} \mathrm{~h}^{-1}$, respectively (see Additional file 1 : Table S7). The multienzyme preparation (standardized with cellulase) appeared as the most suitable for the saccharification of Sugarcane bagasse with the rate of $3.033 \mathrm{mg} \mathrm{mL}^{-1} \mathrm{~h}^{-1}$. The hydrolysis of all the substrates reached to maximum levels in $24 \mathrm{~h}$ except for the hydrolysis of orange peels (see Additional file 1: Fig. S5). Hence, the reaction can be terminated in a shorter period of time compared to the findings by Naseeb et al. (2015). The hydrolysis of pectin released the most amount of reducing sugars than that of any other substrate tested in this study that can be attributed to the pectinolytic potential of the enzyme preparation. The rates of hydrolysis of crude substrates were, however, higher than that of commercially purified CMC and Xylan. Possible synergistic interaction among enzyme activities in the cocktail could be attributed to the efficient hydrolysis of crude substrate than that of purified substrates. Tariq et al. (2018) observed a synergistic action of yeast xylanase over bacterial cellulase preparations for the hydrolysis of untreated Sugarcane bagasse. Degree of synergy also observed by Song et al. (2016) when bioconversion of Corncob powder, Corn straw, and Rice straw were performed by cellulase and xylanases' mixture.

\section{Clarification of orange juice}

Citrus juices are popular throughout the world and contribute to fulfill requirements for vitamin C. During juice extraction, presence of hemicelluloses, pectin, and starch imparts turbidity and viscosity (Lee et al. 2006) that need to be reduced to give juices sufficient clarity (Sharma 2012). Pectinases are largely applied for clarification of juices, whereas a few reports describe role of xylanase in this regard (Sharma 2012). Interestingly, synergism between xylanase and pectinase is also known for its significance in commercial application of the two enzymes. In this study, the multienzyme preparation was standardized to $10 \mathrm{IU} \mathrm{mL} \mathrm{mL}^{-1}$ of xylanase and its potential to clarify orange juice was investigated. The results obtained revealed that the turbidity of orange juice was reduced to $11.19 \%$ within $2 \mathrm{~h}$ of incubation, which is in line with the findings of Nagar et al. (2012) where $10.78 \%$ of pineapple juice clarification was obtained by xylanase. However, the level of clarification was much lower than reported by Ahmed and Sohail (2019) using pectinase preparation from yeast, indicating need of further studies on the multienzyme preparation produced in this study. Viscosity of orange juice also reduced to 5.2 Pa.s from 6.4 Pa.s and acidity reduced to $0.64 \%$.

\section{Conclusion}

Peels of Citrus limetta (CLP) found as the promising substrate for the production of multienzyme preparation by a yeast consortium under solid-state fermentation. Pretreatment of CLP with alkali was proved better than acid pretreatment. The multienzyme preparation had potential to be applied for the saccharification of fruit- and non-fruit-based waste materials. In addition, the multienzyme preparation showed substantial efficacy in the clarification of orange juice.

\section{Supplementary information}

Supplementary information accompanies this paper at https://doi. org/10.1186/s40643-019-0278-0.

Additional file 1: Table S1. Regression coefficient and P-values of endoglucanase (EG), $\beta$-glucosidase (BGL), xylanase (Xyl), pectinase (PEC) and amylase (AMY) for acid pretreated Citrus lametta peels' fermentation. Table S2. Regression coefficient and P-values of endoglucanase (EG), $\beta$-glucosidase (BGL), xylanase (Xyl), pectinase (PEC) and amylase (AMY) for Plackett-Burman of SSF of alkali pretreated substrate. Table S3. Summary of two-way ANOVA. PBD designs executed for fermentation of acid and alkali pretreated Citrus limetta peels were compared to determine suitability of the substrates. Table S4. Analysis of variance (ANOVA) of (a) EG, (b) BGL, (c) Xyl, and (d) AMY production for regression model. Table S5. Optimum conditions for the production of mulienzyme preparation as suggested by the Box Behnken deisgn. The model also predicted values of individual enzyme activities that can be obtained under optimum conditions. An experiment was conducted under optimum conditions and actual values of the enzyme activities are given. Table S6. Analysis of variance (ANOVA) of pectinase (PEC) response for regression model. Table S7. Rate of hydrolysis of various substrates when loaded with multienzyme preparation from the yeast consortium. Fig. S1. Surface plots of EG showing relationship between (a) Moistening agentand pretreatment. (b) Media $\mathrm{pH}$ and pretreatment. (c) Incubation time and pretreatment. (d) Moistening agent and media pH. (e) Moistening agent and incubation time. (f) Media pH and incubation time. Fig. S2. Surface plots of BGL showing relationship between. (a) Moistening agent and pretreatment. (b) Media pH and pretreatment. (c) Incubation time and pretreatment. (d) Moistening agent and media pH. (e) Moistening agent and incubation time. (f) Media pH and incubation time. Fig. S3. Surface plots of XYL showing relationship between (a) Moistening agent and pretreatment. (b) Media pH and pretreatment. (c) Incubation time and pretreatment. (d) Moistening agent and media pH. (e) Moistening agent and incubation time. (f) Media pH and incubation time. Fig. S4. Surface plots of AMY showing relationship between (a) Moistening agent and pretreatment. (b) Media $\mathrm{pH}$ and pretreatment. (c) Incubation time and pretreatment. (d) Moistening agent and media pH. (e) Moistening agent and incubation time. (f) Media pH and incubation time. Fig. S5. Saccharification of apple peels, sugarcane bagasse, banana peels, mosambi peels, mango peels, orange peels, pomegranate peels, CMC, Xylan, Pectin by multienzyme preparation.

\section{Abbreviations}

BBD: Box-Behnken design; BGL: $\beta$-glucosidase; CLP: Citrus limetta peels; CMC: carboxymethyl cellulose; DoE: design of experiment; EG: endoglucanase; Ha: hectare; MSM: mineral salt medium; MT: megaton; PBD: Plackett-Burman design; PCWDEs: plant cell wall degrading enzymes; SDA: Sabouraud's dextrose agar; SSF: solid state fermentation; Xyl: xylanase; YEP: yeast extract peptone. 


\section{Acknowledgements \\ Not applicable.}

\section{Authors' contributions}

MSh performed all the experiments. MS conceived the idea, designed the study, and wrote the manuscript. Both authors read and approved the final manuscript.

\section{Funding}

Funds were received from Third World Academy of Sciences (TWAS) for this work vide Grant number 10-134 to MS

\section{Availability of data and materials}

The data sets used and/or analyzed during the current study are available from the corresponding author on reasonable request.

\section{Ethics approval and consent to participate}

Not applicable.

\section{Consent for publication}

Not applicable.

\section{Competing interests}

The authors declare that they have no competing interests.

\section{Received: 27 September 2019 Accepted: 11 November 2019}

Published online: 19 November 2019

\section{References}

Ahmed A, Sohail M (2019) Characterization of pectinase from Geotrichum candidum AA15 and its potential application in orange juice clarification. J King Saud Univ Sci. https://doi.org/10.1016/j.jksus.2019.07.002

Ahmed A, Khan MN, Ahmad A et al (2019) Optimization of pectinase production from Geotrichum candidum AA15 using response surface methodology. Pak J Bot 51:743-750. https://doi.org/10.30848/PJB2019-2(41)

Arshad ZIM, Amid A, Yusof F et al (2014) Bromelain: an overview of industrial application and purification strategies. Appl Microbiol Biotechnol 98:7283-7297

Brijwani K, Oberoi HS, Vadlani PV (2010) Production of a cellulolytic enzyme system in mixed-culture solid-state fermentation of soybean hulls supplemented with wheat bran. Process Biochem. https://doi.org/10.1016/j. procbio.2009.08.015

Chew KW, Yap JY, Show PL et al (2017) Microalgae biorefinery: high value products perspectives. Bioresour Technol. https://doi.org/10.1016/j.biort ech.2017.01.006

Cui F, Zhao L (2012) Optimization of xylanase production from Penicillium sp. WX-Z1 by a two-step statistical strategy: Plackett-Burman and BoxBehnken experimental des. Int J Mol Sci. https://doi.org/10.3390/ijms1 30810630

Deswal D, Khasa YP, Kuhad RC (2011) Optimization of cellulase production by a brown rot fungus Fomitopsis sp. RCK2010 under solid state fermentation. Bioresour Technol. https://doi.org/10.1016/j.biortech.2011.03.032

Ferreira JA, Mahboubi A, Lennartsson PR, Taherzadeh MJ (2016) Waste biorefineries using filamentous ascomycetes fungi: present status and future prospects. Bioresour Technol 215:334-345

Grohmann K, Cameron RG, Buslig BS (1995) Fractionation and pretreatment of orange peel by dilute acid hydrolysis. Bioresour Technol. https://doi. org/10.1016/0960-8524(95)00121-2

Herrero AA, Gomez RF, Roberts MF (1985) 31P NMR studies of Clostridium thermocellum. Mechanism of end product inhibition by ethanol. J Biol Chem 260:7442-7451

Hmad IB, Abdeljalil S, Saibi W et al (2014) Medium initial pH and carbon source stimulate differential alkaline cellulase time course production in Stachybotrys microspora. Appl Biochem Biotechnol. https://doi.org/10.1007/ s12010-013-0705-1

Lee WC, Yusof S, Hamid NSA, Baharin BS (2006) Optimizing conditions for enzymatic clarification of banana juice using response surface methodology (RSM). J Food Eng. https://doi.org/10.1016/j.jfoodeng.2005.01.005
Li PJ, Xia JL, Shan Y, Nie ZY (2015) Comparative study of multi-enzyme production from typical agro-industrial residues and ultrasound-assisted extraction of crude enzyme in fermentation with Aspergillus japonicus PJ01. Bioprocess Biosyst Eng. https://doi.org/10.1007/s00449-015-1442-3

Lynd LR, Weimer PJ, van ZyI WH, Pretorius IS (2002) Microbial cellulose utilization: fundamentals and biotechnology. Microbiol Mol Biol Rev. https:// doi.org/10.1128/mmbr.66.4.739.2002

Madrera RR, Bedriñana RP, Valles BS (2015) Production and characterization of aroma compounds from apple pomace by solid-state fermentation with selected yeasts. LWT Food Sci Technol. https://doi.org/10.1016/j. Iwt.2015.07.056

Manan MA, Webb C (2017) Modern microbial solid state fermentation technology for future biorefineries for the production of added-value products. Biofuel Res J 4:730-740

Mantzouridou FT, Paraskevopoulou A, Lalou S (2015) Yeast flavour production by solid state fermentation of orange peel waste. Biochem Eng J. https:// doi.org/10.1016/j.bej.2015.04.013

Miller GL (1959) Use of dinitrosalicylic acid reagent for determination of reducing sugar. Anal Chem. https://doi.org/10.1021/ac60147a030

Nagar S, Mittal A, Gupta VK (2012) Enzymatic clarification of fruit juices (apple, pineapple, and tomato) using purified Bacillus pumilus SV-85S xylanase. Biotechnol Bioprocess Eng. https://doi.org/10.1007/s12257-012-0375-9

Naseeb S, Sohail M, Ahmad A, Khan SA (2015) Production of xylanases and cellulases by Aspergillus fumigatus MS16 using crude lignocellulosic substrates. Pak J Bot 47:779-784

Oberoi HS, Vadlani PV, Madl RL et al (2010) Ethanol production from orange peels: two-stage hydrolysis and fermentation studies using optimized parameters through experimental design. J Agric Food Chem. https://doi. org/10.1021/jf903163t

Oberoi HS, Vadlani PV, Nanjundaswamy A et al (2011) Enhanced ethanol production from Kinnow mandarin (Citrus reticulata) waste via a statistically optimized simultaneous saccharification and fermentation process. Bioresour Technol. https://doi.org/10.1016/j.biortech.2010.08.111

Pirzadah T, Garg S, Singh J et al (2014) Characterization of Actinomycetes and Trichoderma spp. for cellulase production utilizing crude substrates by response surface methodology. Springerplus. https://doi. org/10.1186/2193-1801-3-622

Qadir F, Shariq M, Ahmed A, Sohail M (2018) Evaluation of a yeast co-culture for cellulase and xylanase production under solid state fermentation of sugarcane bagasse using multivariate approach. Ind Crops Prod. https:// doi.org/10.1016/j.indcrop.2018.07.021

Rahnama N, Mamat S, Shah UKM et al (2013) Effect of alkali pretreatment of rice straw on cellulase and xylanase production by local Trichoderma harzianum SNRS3 under solid state fermentation. BioResources. https:// doi.org/10.15376/biores.8.2.2881-2896

Raimbault M (1998) General and microbiological aspects of solid substrate fermentation. Electron J Biotechnol 1:1-15

Rehman S, Aslam H, Ahmad A et al (2014) Production of plant cell wall degrading enzymes by monoculture and co-culture of Aspergillus niger and Aspergillus terreus under SSF of banana peels. Brazilian J Microbiol 45:1485-1492

Rosyida VT, Indrianingsih AW, Maryana R, Wahono SK (2015) Effect of temperature and fermentation time of crude cellulase production by Trichoderma reesei on straw substrate. Energy Procedia 65:368-371

Sadhu S (2013) Cellulase production by bacteria: a review. Br Microbiol Res J. https://doi.org/10.9734/bmrj/2013/2367

Sagar NA, Pareek S, Sharma S et al (2018) Fruit and vegetable waste: bioactive compounds, their extraction, and possible utilization. Compr Rev Food Sci Food Saf. https://doi.org/10.1111/1541-4337.12330

Salihu A, Alam MZ, Abdulkarim MI, Salleh HM (2011) Optimization of lipase production by Candida cylindracea in palm oil mill effluent based medium using statistical experimental design. J Mol Catal B Enzym. https ://doi.org/10.1016/j.molcatb.2010.12.012

Sandhu SK, Oberoi HS, Dhaliwal SS et al (2012) Ethanol production from Kinnow mandarin (Citrus reticulata) peels via simultaneous saccharification and fermentation using crude enzyme produced by Aspergillus oryzae and the thermotolerant Pichia kudriavzevii strain. Ann Microbiol. https:// doi.org/10.1007/s13213-011-0302-x

Sankaran R, Bong JH, Chow YH et al (2019) Reverse micellar system in protein recovery - a review of the latest developments. Curr Protein Pept Sci. https://doi.org/10.2174/1389203720666190628142203 
Shariq M, Sohail M (2018) Application of Candida tropicalis MK-160 for the production of xylanase and ethanol. J King Saud Univ Sci. https://doi. org/10.1016/j.jksus.2018.04.009

Shariq M, Sohail M (2020) Production of cellulase and xylanase from Candida tropicalis (MK-118) on purified and crude substrates. Pak J Bot. https://doi. org/10.30848/PJB2020-1(14)

Shariq M, Muhammad F, Ahmad A et al (2018) Production and characterization of endoglucanase from an indigenous yeast strain. Pak J Bot 50:2413-2421

Sharma PK (2012) Optimization of process parameters for fruit juice clarification using silica immobilized xylanase from Pseudomonas sp. Pure Appl Biol. https://doi.org/10.19045/bspab.2012.12006

Sharma S, Sharma J, Mandhan RP (2014) Lucrative pectinase production by novel strain Pseudozyma sp. SPJ with statistical optimization techniques using agro-industrial residues. Front Biol. https://doi.org/10.1007/s1151 5-014-1316-0

Song HT, Gao Y, Yang YM et al (2016) Synergistic effect of cellulase and xylanase during hydrolysis of natural lignocellulosic substrates. Bioresour Technol. https://doi.org/10.1016/j.biortech.2016.08.035

Sutherland IW (2001) Biofilm exopolysaccharides: a strong and sticky framework. Microbiology 147:3-9

Suwannarangsee S, Arnthong J, Eurwilaichitr L, Champreda V (2014) Production and characterization of multi-polysaccharide degrading enzymes from Aspergillus aculeatus BCC199 for saccharification of agricultural residues. J Microbiol Biotechnol. https://doi.org/10.4014/jmb.1406.06050
Tariq R, Ansari I, Qadir F et al (2018) Optimization of endoglucanase production from thermophilic strain of Bacillus licheniformis RT-17 and its application for saccharification of sugarcane bagasse. Pak J Bot 50:807-816

Yahya S, Jahangir S, Shaukat SS et al (2016) Production optimization by using Plackett-Burman design and partial characterization of amylase from Aspergillus tubingensis SY 1. Pak J Bot 48:2557

Yasin Ashraf M, Ashraf M, Akhtar M et al (2013) Improvement in yield, quality and reduction in fruit drop in Kinnow (Citrus reticulata Blanco) by exogenous application of plant growth regulators, potassium and zinc. Pak J Bot 45:433-440

Yoon LW, Ang TN, Ngoh GC, Chua ASM (2014) Fungal solid-state fermentation and various methods of enhancement in cellulase production. Biomass Bioenergy 67:319-338

Zhang C, Xing XH, Liu MS (2004) Production of multienzymes consisting of alkaline amylase and cellulase by mixed alkalophilic culture and their potential use in the saccharification of sweet potato. Biochem Eng J. https://doi.org/10.1016/j.bej.2004.01.001

\section{Publisher's Note}

Springer Nature remains neutral with regard to jurisdictional claims in published maps and institutional affiliations.

\section{Submit your manuscript to a SpringerOpen ${ }^{\odot}$ journal and benefit from:}

- Convenient online submission

- Rigorous peer review

- Open access: articles freely available online

- High visibility within the field

- Retaining the copyright to your article

Submit your next manuscript at $\boldsymbol{\nabla}$ springeropen.com 